\title{
Revisiting the "Gresham's Law": Examining the Mechanism of the Dual Identities of Social Enterprise on Social Governance
}

\author{
Qing Miao ${ }^{1,}$ Yixing Zhao ${ }^{2 *}$ \\ ${ }^{1}$ Center of Social Welfare and Governance, Academy of Social Governance, Zhejiang University, School of Public \\ Affairs, room 922, Zijin' gang Campus, Zhejiang, China. \\ ${ }^{2}$ Zhejiang University, School of Public Affairs, room 922, Zijin' gang Campus, Zhejiang, China. \\ *Corresponding author.Email: edbar_zyx@foxmail.com
}

\begin{abstract}
The profit-driven orientation of merchants and the information asymmetry among consumers inevitably lead to the market failure of "bad money drives out good", which is well-known as "Gresham's Law". Based on information share theory and social enterprise theory, we put forward dual identities of social enterprise, which are "Good Product" Broker and "Bad Product" Supervisor. Through the in-depth analysis of the emerging case - the "Daddylab", we analyse the information exchange mechanism among "suppliers, enterprises and consumers", and verify the dual identities of social enterprises and the stage characteristics, and reveal the process mechanism of the "good money drives out bad" that is promoted by social enterprises.
\end{abstract}

Keywords: Social Governance, Social Enterprise, Dual Identities, Gresham's Law

\section{INTRODUCTION}

In economics, "Gresham's law" is a monetary principle stating that "bad money drives out good". The problem of bad money driving out good stems from information asymmetry. Information asymmetry usually occurs when one party knows more about some information than others [1]. Information asymmetry occurs when it is difficult for downstream organizations or individuals to evaluate the performance of their counterparties or to predict the market environment [2]. Information asymmetry may be exploited by suppliers or merchants. On the one hand, suppliers may make false claims about their skills or product quality [3]. On the other hand, merchants may distort market conditions to cover up their default liability. In other words, the mismatch of information between the parties opens the way for opportunism, as shown in Figure 1 [4]. In order to minimize this behavior, suppliers, merchants, and consumers have to invest in information monitoring mechanisms, which greatly increases transaction costs [5].

Is there an organizational form that can realize the information sharing between suppliers, merchants and consumers, thereby restoring the true value of 'good money'? Social enterprise refers to an organization that uses commercial activities as a means to pursue social goals [6]. Formally, social enterprises are different from traditional commercial enterprises and non-profit organizations because they have the dual bottom line of social mission and economic benefits (Figure 2) [7]. Generally speaking, social enterprises have a certain business model to solve a specific social problem. They are not seeking to maximize the interests of shareholders and business owners, but to solve social prblems. The main goal is to provide public welfare or social services [8], such as providing products or services with social responsibility or promoting environmental protection, and providing employment opportunities for vulnerable groups, building shops designed to promote fair trade, etc. [9].

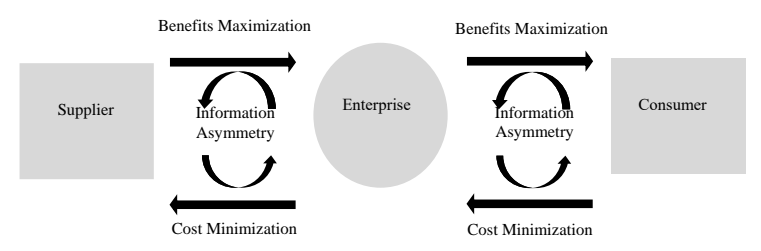

Figure 1 The traditional model of commercial relationship based on information asymmetry. 
In the commercial field, all parties in the tripartite relationship of supplier to merchant and merchant to consumer have a demand for maximizing benefits, which leads to "bad money drives out good". However, due to its own uniqueness, social enterprises have theoretical possibilities in solving such problems. This paper analyses a new case in the commercial field-"Dad dylab", and answers two core questions: First, how do social enterprises start from social pain points and fulfill their social mission? Second, how can social enterprises share information to drive out bad money and rejuvenate good money.

\section{CONCEPTUAL MODEL}

The dual bottom line of social enterprises makes it no longer oriented to seeking benefits. The mission of solving social problems may enable it to realize information sharing, reduce opportunistic behavior, and thus reduce the cost of establishing a monitoring mechanism in the traditional way. Therefore, based on the above theoretical background, this paper believes that there are theoretical possibilities for the two roles (bad product supervisor and good product broker) that social enterprises play in the transaction link (Figure 2).

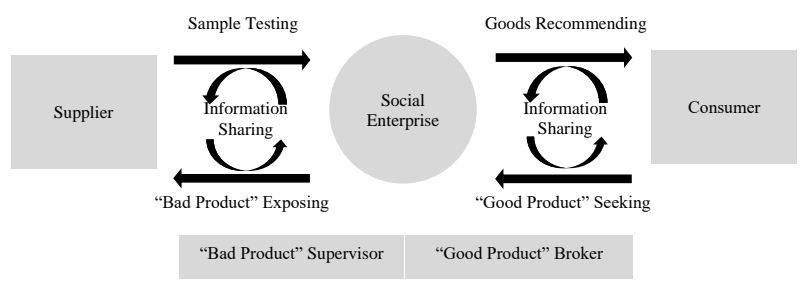

Figure 2 The dual identities of social enterprise within the commercial relationship.

\subsection{Supervisor of "Bad Product"}

According to the bottom line of social enterprises (grasping social pain points), it can be inferred that when information asymmetry occurs between the upstream suppliers and the midstream companies, social enterprises can achieve the possibility of information sharing spontaneously. Specifically, in order to realize their mission, social enterprises will spontaneously test the products and services that are provided by existing manufacturers. If the testing fails, they will share this information to expose the existing inferior products. Once such information sharing is realized, the transaction behavior is transparent, and transaction costs may be reduced, so as to distinguish good money from bad money in the market and restore the value of good money. Therefore, this paper believes that when a social enterprise replaces a traditional enterprise and is placed in the tripartite commodity trading link, it will play the role of a supervisor of inferior products.

\subsection{Broker of "Good Product"}

According to the bottom line of social enterprises (self-sustain), it can be inferred that when information asymmetry occurs between downstream consumers and midstream enterprises, social enterprises can also realize information sharing spontaneously. When downstream consumers want to buy "good product" in the market, but they are not satisfied with the asymmetry of the information, they find it impossible to find a good product, resulting in the problem of insufficient supply of "good product" in the transaction link. The significance of social enterprises is to meet these needs of consumers. It recommends "good product" to consumers by publishing product information, etc., and realizes information sharing, which provides the possibility of cracking the dilemma of "bad money drives out good". Therefore, this paper believes that, in the field of commodity, due to the consistency of their missions and information sharing demands, social enterprises are likely to play the role of good product brokers, which can either recommend qualified products that have passed the test, or provide excellent products and services themselves.

\section{QUALITATIVE STUDY}

Daddylab was established on January 7, 2015. It is rooted in such social pain point: the public is not assured of all kinds of products in life, and harmful products are constantly emerging.

The development of "Daddylab" has gone through two development stages. The first stage is the "public welfare" output period. At this stage, the funding for the "Daddylab" came from the founder--Wei. However, the cost of product testing is high, but there is no income, so funding problems arise. As a result, there has been a change from "public welfare" to "crowdfunding". The founder relied on his popularity to launch crowdfunding, but by the end of 2015 , he had only received more than 60,000 yuan funds, which was not enough to maintain the growing demand for testing. After the crowdfunding model was frustrated, "Daddylab" tried to find microshareholders to conduct equity crowdfunding in January 2016. Each share was 10,000 yuan, and each shareholder was limited to 2 shares. By the end of 2016, 2 million yuan had been raised.

The second stage began in February 2016 and continues to this day, as a period of "Self-sustain". After having hundreds of micro-shareholders, Wei realized that only a survival can solve more social problems. In order to achieve self-sustain, "Daddylab" launched the "Dad Mall". Depending on the online store, the exhibitors in the mall are all products that have passed the test. At this time, the company's positioning has become a good product broker. Its value creation model has become releasing excellent product information, promoting the 
industry's ecological norms. While continuously evaluating and accumulating credibility, continuous growth in sales has provided a source of motivation for public welfare behavior. At present, the annual turnover of the "Dad Mall" reaches 10 million yuan, and the development trend is promising.

\section{CASE STUDY}

\subsection{Stage 1: "Public Welfare” Output}

\subsection{1. “Bad Product” Exposure}

On the path of exposing "bad product", Daddylab, as a social enterprise, has a social mission to keep children and society away from toxic products. By collecting testing willingness, crowdfunding testing costs, implementing professional testing, publishing product blacklists and white products The list and other steps effectively distinguish "bad product" from "good product" provided by suppliers in the market and restore the value of good coins.

\subsection{2. "Bad Product” Supervisor}

On the path of exposing "bad product", Daddylab, as a social enterprise, has a social mission to keep children and society away from toxic products. By collecting testing willingness, crowdfunding testing costs, implementing professional testing, publishing product blacklists and white products The list and other steps effectively distinguish "bad product" from "good product" provided by suppliers in the market and restore the value of good coins.

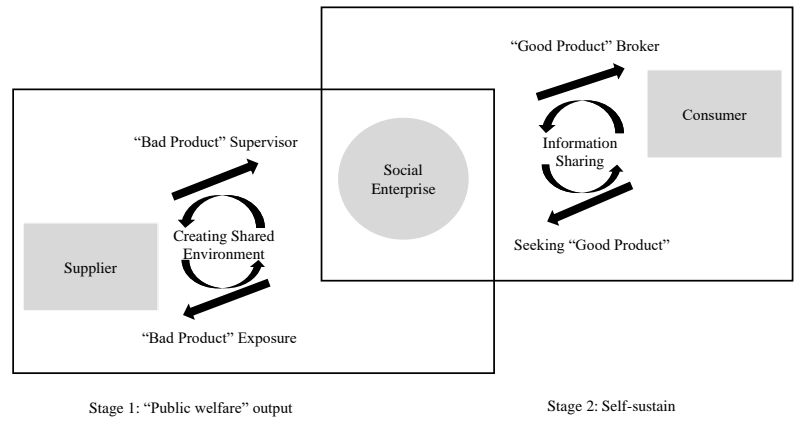

Figure 3 A new two-stage model of dual identities of social enterprise.

Daddylab has created an environment for information sharing. In order to solve the asymmetry of information, Wei made full use of the advantages of the Internet to establish a "Daddylab" WeChat group. Wei often talks with parents in the WeChat group to discuss cases of toxic and hazardous items in life and how to avoid them. harm. At the same time, Wei will also consult parents' suggestions on what parents want to test. "Daddylab" will raise funds to test a series of products in this industry.

\subsection{Stage 2: Self-sustain}

At this stage, the "Daddylab" has also undergone a change of identity, from a "bad product" supervisor to a "good product" broker. The so-called broker means that it distributes marketing information for "good product", obtains revenue and then maintains development.

\subsubsection{Seeking "Good Product”}

On the path of seeking "good product", "Daddylab" innovates in the development model in order to further meet consumer demand for safe products. In cooperation with the e-commerce platform, the Dad Mall opened, and qualified products were purchased. Dad Mall does not make money through the difference, only recovers the cost price of the products, the packaging box and labor costs, gives consumers the full autonomy to participate.

\subsection{2. "Good Product” Broker}

On the path of "good product" broker, "Daddylab" realizes both economic benefits and social benefits through the marketing strategy of safe products. It has a unique quality control system that rolls from time to time to ensure that suppliers can continue to produce products that meet Dad's standards. The operating mode is costsharing. For every product purchased by the Dad Mall. the user purchases a certain percentage of the cost for the quality control and testing system. There is also consumer participation during the spot check. The system randomly selects consumers who purchase products, and they will serve as test senders.

On the path of information sharing, "Daddylab" has developed a solution mechanism for information asymmetry. On product information sharing, a series of product test reports, as well as the testing and listing process, will be announced in Dad Mall. For example, a pen bag will explain why other products are not required (a large amount of o-benzene exceeds the standard and a heavy metal exceeds the standard), and explain The products on the shelves are now made of materials and production standards (European Union safety standards), as well as the Daddylab's inspection results.

\section{CONCLUSION}

In this paper, through a detailed introduction to the typical case of social enterprises--"Daddylab", this paper analyzes the dual identities of social enterprises and their role in resolving information asymmetry and realizing effective markets in the field of trade.

\subsection{Enhancing the Market Information Sharing}

Social enterprises are not only pursuing economic benefits, but achieving social missions in a sustainable 
way. On the one hand, social enterprises provide sufficient information for upstream and downstream commodity exchanges to maximize social value. On the other hand, the foundation of a social enterprise is to follow its mission to achieve sufficient information sharing and build social trust. Therefore, the new organizational form of social enterprise brings the possibility of information sharing.

\subsection{Fostering the Effective Markets}

Social enterprises have improved the industry ecology by creating a good atmosphere of "good money drives out bad", effectively responding to social problems caused by market failure, promoting the healthy development of the market, and fostering an effective market. For example, "Daddylab" adopted the strategy of good money drives out bad, formulated relevant product testing standards, set up a quality control system, and provided upstream suppliers with rules and motivation for producing high-quality and qualified products, which has become a "bad product" supervisor.

\subsection{Alleviating Industrial Failure}

Information asymmetries often exist between government departments and the public. On the one hand, there are lags and distortions when public realities reach the hands of decision makers. On the other hand, the government is in a strong position of information, resulting in the public's limited understanding of government information. The asymmetry of information between the two sides leads to the lag of government decision-making, which affects the efficiency of economic operation. At this time, government failure occurs. Social enterprises can become an intermediate link for transmitting information. For example, the "daddy evaluation" acts as an intermediary between the public and the government. It not only exposes toxic products, so parents can understand the situation and purchase Safe and assured products will also inform the government of toxic products, and relevant government departments will also actively respond and increase supervision.

\section{REFERENCES}

[1] Cui J, Jo H and $\mathrm{Na} \mathrm{H} 2018$ Does corporate social responsibility affect information asymmetry (Journal of Business Ethics Vol 3) pp 549-572

[2] Lambert R A, Leuz C and Verrecchia R E 2012 Information asymmetry, information precision, and the cost of capital (Review of Finance Vol 1) pp 129

[3] Courtney C, Dutta S and Li Y 2017 Resolving information asymmetry: Signaling, endorsement, and crowdfunding success (Entrepreneurship Theory and Practice Vol 2) pp 265-290

[4] Ma P, Shang J and Wang H 2017 Enhancing corporate social responsibility: Contract design under information asymmetry. (Omega Vol 3) pp 19. 30

[5] Crosno J L and Brown J R 2015 A meta-analytic review of the effects of organizational control in marketing exchange relationships (Journal of The Academy of Marketing Science Vol 3) pp 297-314

[6] Santos F M 2012 A positive theory of social entrepreneurship (Journal of Business Ethics Vol.3) pp 335-351

[7] Miao Qing 2014 Social Enterprises: Linking Business with Social Benefits (Hangzhou: Zhejiang University Press) pp 14-25

[8] Pan Xiaojuan 2011 The preliminary study of social enterprise (Chinese Public Administration Vol 7) pp 20-23

[9] Saebi T, Foss N J and Linder S 2019 Social entrepreneurship research: Past achievements and future promises (Journal of Management Vol 1) pp $70-95$ 